\title{
利用控制实验研究植物物候对气候变化的响应综述
}

\author{
胡 植 ${ }^{1,2}$, 王焕昫 ${ }^{1, *}$, 戴君虎 ${ }^{1,2}$, 葛全胜 ${ }^{1}$ \\ 1 中国科学院地理科学与资源研究所陆地表层格局与模拟重点实验室, 北京 100101 \\ 2 中国科学院大学, 北京 100049
}

摘要:物候是植物在长期适应环境过程中形成的生长发育节点。长时间地面物候观测数据表明,近 50 年全球乔木、灌木、草本 植物的春季物候期受温度升高、降水与辐射变化等影响, 以每 10 年 $2 \mathrm{~d}$ 到 $10 \mathrm{~d}$ 的速率提前。但因植物物候响应气候因子的机 制仍不清楚,导致对未来气候变化情景下的植物物候变化预测存在较大的不确定性。在此背景下,控制实验成为探究气候因子 对植物物候影响机制的重要手段。综述了物候控制实验中不同气候因子 (温度、水分、光照等) 的控制方法。总结了目前为止 控制实验在植物物候对气候因子响应方面得到的重要结论, 发现植物春季物候期 (展叶、开花等) 主要受冷激、驱动温度与光周 期的影响,秋季物候期 (叶变色和落叶) 主要受低温、短日照与水分胁迫的影响。提出未来物候控制实验应重点解决木本植物 在秋季进人休眠的时间点确定、低温和短日照对木本植物秋季物候的交互作用量化、草本植物春秋季物候的影响因子识别等科 学问题。

关键词: 植物物候; 气候因子;温度;水分;光照; 控制实验; 气候变化

\section{Using controlled experiments to investigate plant phenology in response to climate change: progress and prospects}

\author{
HU Zhi ${ }^{1,2}$, WANG Huanjiong ${ }^{1, *}$, DAI Junhu ${ }^{1,2}$, GE Quansheng ${ }^{1}$ \\ 1 Key Laboratory of Land Surface Pattern and Simulation, Institute of Geographic Sciences and Natural Resources Research, Chinese Academy of Sciences, \\ Beijing 100101, China \\ 2 University of Chinese Academy of Sciences, Beijing 100049, China
}

\begin{abstract}
Phenology is the occurrence time of plant growth and development events formed in the process of long-term adaptation to the environment. The long-term phenological observation data showed that the spring phenophases of trees, shrubs, and herbs advanced by 2 to 10 days per decade over the past 50 years, affected by temperature rises, precipitation, and radiation changes. However, the mechanism of plant phenology in response to climatic factors is still unclear, leading to greater uncertainty in predicting plant phenological changes under future climate change scenarios. In this context, the controlled experiments have become an important way to explore the mechanism of climatic factors affecting plant phenology. This study summarized firstly the control methods of different climatic factors (temperature, moisture, light, etc.) in the phenological experiments. Second, we summarized the critical conclusions of the controlled experiments about the response of plant phenology to climatic factors so far and found that the spring phenophases of plants (leaf-out, flowering, etc.) were mainly affected by chilling, forcing temperature and photoperiod, and the autumn phenophases (leaf coloring and fall) were mainly driven by low temperature, short daylength, and water stress. Finally, the study proposed that future controlled
\end{abstract}

基金项目: 国家重点研发计划 (2018YFA0606103) ; 国家自然科学基金项目 (41871032,41807438); 中科院地理资源所可桢杰出青年学者计划 (2018RC101)

收稿日期: 2020-12-07; 网络出版日期:2021-07-23

* 通讯作者 Corresponding author.E-mail: wanghj@ igsnrr.ac.cn 
experiments should focus on determining the time for woody plants to enter dormancy in autumn, quantifying the interaction of low temperature and short daylength on autumn phenophase of woody plants, and identifying influencing factors for spring and autumn phenophases of herbaceous plants.

Key Words : plant phenology ; climatic factors ; temperature; moisture; light; controlled experiment; climate change

工业革命以来,全球发生了以气候变暖为主要特征的变化。2019 年全球平均温度较工业化前升高了约 $1.1^{\circ} \mathrm{C}$, 同时 2015-2019 年是有完整气象观测记录以来最暖的五个年份 ${ }^{[1]}$ 。受气候变暖影响, 过去几十年来 北半球不同类群 (木本植物、草本植物、昆虫、鸟类、两栖动物等) 的春季物候期显著提前、秋季物候期推 迟 ${ }^{[2-5]}$ 。植物物候变化影响了陆地生态系统碳吸收 ${ }^{[6]}$ 与水循环 ${ }^{[7]}$ 等过程, 同时不同营养级间物候变化的差异 还改变了生态系统种间关系 ${ }^{[8]}$ 。因此,植物物候期不仅是气候变化的敏感指示器, 还是影响生态系统结构与 功能的关键参数。

传统的植物物候学研究主要依赖于地面观测、近地面物候相机监测和遥感监测这三种数据源。地面物候 观测主要通过对小范围内的植物进行多年连续的目视观测, 记录植物生长发育事件发生的时间。利用长时间 地面观测资料可研究物候期的年际变化与气候因子的关系 ${ }^{[9-12]}$ 。由于地面物候数据需消耗较多的人力, 近地 面传感器开始应用于物候观测 [13-14]。近地面传感器主要是利用相机对某一固定区域进行连续拍照, 获取不 同波段 (主要以红、绿、蓝及近红外为主) 的长期监测数据。利用遥感数据研究物候具有全空间覆盖的特点,

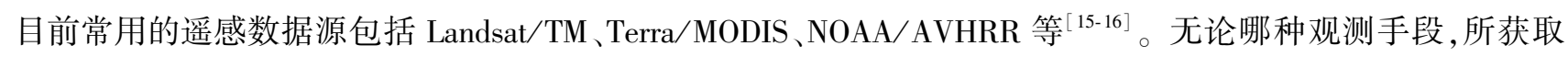
的植物物候期都受多种气候因子综合作用的影响。例如, 某一年的展叶始期受到季前气温、光照、降水等环境 因子的综合影响。基于这三种数据源的物候变化归因只能依靠统计方法区分各因子的作用,但各气候因子对 物候的交互作用机制仍难以厘清。

为研究物候期发生的生理生态机制, 控制实验开始在物候学研究中广泛应用。控制实验的优点在于能够 精准的控制各环境因子, 既有助于排除其他因子的影响, 识别单因子对物候期的作用, 又能识别多因子的交互 作用。物候控制实验的研究对象主要以木本植物 (幼苗、枝条和成年个体) 和草本植物的发芽、展叶、开花与 叶变色等物候期为主。以木本植物枝条与幼苗为对象的实验主要在室内进行 (置于温室或生长箱内), 观测 不同气候因子对物候的影响。而针对木本植物成年个体与草本植物的物候控制实验主要在野外进行。目前 控制实验研究中所涉及的气候因子主要包括温度、光照、湿度等。

近年来, 利用控制实验研究植物物候对气候变化的响应的文献逐渐增多, 极大丰富了对气候因子调控植 物物候的认识。但尚未有研究对物候控制实验的方法与进展进行系统总结与梳理。物候控制实验已经获得 的基本认识以及未来的研究方向仍不明确。因此, 本文综述了已有物候控制实验研究中对不同气候因子(光 照、温度和水分) 的控制方法, 以及在植物物候对气候因子的响应方面获得的重要结论, 最后提出了未来物候 控制实验研究的主要发展方向。

\section{1 物候控制实验中涉及的气候因子}

\section{1 驱动温度}

因温度升高是全球变化的最显著特征,大部分控制实验研究了驱动温度变化对植物物候的影响。为与植 物休眠期经历的低温相区别, 以往文献将休眠解除后, 有利于植物生长发育的适宜温度称之为驱动温 度 ${ }^{[17-18]}$ 。在室内, 最常用的驱动温度控制方法是利用生长箱或温室中的控温设备(空调等) 来调节温度, 观测 植物物候对温度变化的响应。生长箱指用于培养植物等的箱体装置, 采用微电脑控制器, 精确控制箱体内的 温度。由于生长箱体积较小 (1000 L 左右), 在应用于物候控制实验时只适用于草本植物或木本植物的枝条 和幼苗。例如, 有研究通过生长箱实验对比了在早春采集的木本植物枝条在不同驱动温度 $(5 、 10 、 15 、 20 、 25$ 、 
$\left.30^{\circ} \mathrm{C}\right)$ 下开花物候的差异 ${ }^{[19]}$ 。除设定恒定的温度外,也有研究通过设定不同的昼夜温度, 探究白天与夜晚增 温的有效性是否存在差异 ${ }^{[20]}$ 。具备类似温度控制功能的还包括具有防寒、透光等功能的温室。如 Partanen 等 ${ }^{[21]}$ 在温室中通过设置 $10^{\circ} \mathrm{C}$ 恒温及昼夜波动 $\left(15 / 5 、 20 / 10^{\circ} \mathrm{C}\right)$ 两种温度模式, 探讨了植物物候期对昼夜温差 的响应。

除室内控温实验外,在野外通常采用增温装置进行温度控制, 如开顶箱 (主动式、被动式)、土壤加热电 缆、红外线辐射器等 ${ }^{[22]}$ 。被动式开顶箱主要通过外部框架和透明挡板形成圆台或六棱台的半封闭空间来提 高箱体内部温度 (增温幅度通过箱体高度来控制) , 而主动式开顶箱是通过半封闭的框架空间和电加热的共 同作用来提高箱体内部温度。相较于主动式开顶箱, 被动式开顶箱更为经济、简单易行, 因此在体型普遍较小 的草本植物上应用最广泛。例如,有研究在西藏中部的高山草甸地区利用被动式开顶箱对优势物种实施增温 处理 ${ }^{[23]}$, 观测金露梅 (Potentilla fruticosa) 和钉柱委陵菜 (Potentilla saundersiana) 开花物候对增温的响应。但 是, 被动式开顶箱在增加温度的同时,可能对风速、降雨量等产生干扰。其它增温方式主要是主动式增温,即 利用红外线的电磁辐射热传递效应实现增温。例如, 珊丹 ${ }^{[24]}$ 在内蒙古荒漠草原悬挂红外辐射器来加热, 观测 样地内六种主要植物的开花物候及生长季长度对增温的响应。主动式增温也适用于木本植物的冠层或根系。 例如, 在日本的温带森林中选取了三棵 18-20 m 的蒙古栋 ( Quercus crispula), 在其顶端枝条上加绑增温 $5^{\circ} \mathrm{C}$ 的加热电缆, 探究枝条增温对叶片衰落期的影响 ${ }^{[25]}$ 。在加拿大鬼北克省, 通过在深约 $20 \mathrm{~cm}$ 的土壤中埋设加

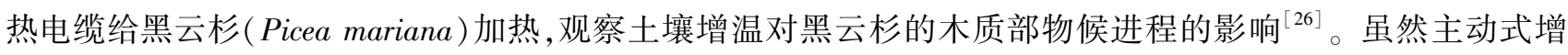
温的红外辐射器能够更为真实地模拟全球气候变化情况, 但与被动式增温相比它对电力需求大且加热面积 有限。

\section{2 冷激}

温带地区的多年生木本或草本植物在秋冬季会进人自然休眠期,经历冬季一定时长的低温之后才能解除 自然休眠 ${ }^{[27]}$ 。低温诱导休眠解除的过程在文献中称为冷激 ${ }^{[28-30]}$, 通常以植物在休眠期经历的低温累积时间 (小时或天数)来定量描述。室内控制实验中对冷激的处理主要是在生长箱设定不同冷激温度,并对采集的 枝条样本处理不同的时间。例如,通过生长箱设定冷激温度为 $1.5^{\circ} \mathrm{C}$ 与 $4^{\circ} \mathrm{C}$, 处理 $30 \mathrm{~d}$ 后, 再置于合适温度条 件下,可对比枝条接受到的冷激量对后续展叶与开花时间的影响 ${ }^{[31]}$ 。

在室外,通常采用自然冷激处理,即通过控制采样时间来获得不同冷激处理的样本。例如 Laube 等 ${ }^{[32]}$ 在 2011 年 12 月 14 日到 2012 年 3 月 14 日的时段内,每隔约 6 周从德国同一森林站点采集一次植物枝条,根据 其暴露在自然冷激条件下的时间差异划分 3 种冷激程度。在中国亚热带地区也进行过类似实验 ${ }^{[33]}$ 。

\section{3 光照条件}

光照对植物物候的影响非常复杂, 光的三个特性均会影响物候期,包括光周期、光照强度和光谱。光周期 是指昼夜周期中昼长和夜长的季节性变化。光照强度是指单位面积所接受的可见光通量。光谱则是指光源 不同波长的光所占的比例。

光周期的控制中应用最为广泛的是生长箱。在生长箱中, 通常有金属卤化物灯、白炽灯等维持光照,通过 人工或微电脑控制不同时长的光照循环来实现光周期变化。例如 Zohner 等 ${ }^{\left[{ }^{[3]}\right.}$ 通过生长箱设定 $8 \mathrm{~h}$ 和 $16 \mathrm{~h}$ 两 种不同的昼长来观测欧洲山毛榉 (Fagus sylvatica)、欧洲七叶树 (Aesculus hippocastanum) 和挪威云杉 (Picea abies ) 的物候。也有研究通过在培养箱中逐渐增加昼长的方式, 模拟自然条件下昼长逐渐延长的条件 ${ }^{[35]}$ 。在 野外环境下,一般采用遮光方法控制光周期。例如,在每天特定的时间段,给室外成年植株的枝条上套上黑色 不透光袋子,直接控制枝条接受光照的时间, 并用相同的透明袋子作为对照, 探究昼长缩短对物候的影响 ${ }^{[34]}$ 。 $\mathrm{Fu}$ 等 ${ }^{[36]}$ 也采用类似套袋方法研究了光周期对植物展叶期的影响。

光照强度的控制既可通过不同瓦数的光源实现, 也可利用白色棉布罩减弱光强。例如, Caffarra 等 ${ }^{[37]}$ 利 用生长箱, 对比了不同光强下欧洲山毛榉萌芽期的变化。有实验在温室中使用遮阳布研究了降低光照强度对 挪威云杉春季物候期的影响 ${ }^{[38]}$ 。 
光谱的控制通常通过改变光源来释放不同谱段的光。例如, Brelsford 等 ${ }^{[39]}$ 利用生长箱中 LED 灯的布置, 设定有蓝光和无蓝光照射两种光照条件, 观测植物物候对蓝光的响应。也有实验使用滤光片改变红光与近红 外波段的比例 (R:FR), 研究 R:FR 值的减小对欧洲白华 (Betula pendula) 春季萌芽的影响 ${ }^{[40]}$ 。

\section{4 水分条件}

在研究水分条件对物候影响时,主要控制两个变量,即空气湿度和土壤湿度。在室内实验中,一般将吸水 的棉芯放人生长箱, 通过棉芯的数量来控制水分蒸发量, 以此来实现空气湿度的控制 ${ }^{[41]}$ 。另外在培养箱中定 期喷水与不喷水处理,也能实现空气湿度的控制。土壤湿度通常通过不同的浇水量和浇水频率来控制 ${ }^{[42]}$ 。 Khan 等 ${ }^{[43]}$ 在研究土壤湿度对花旗松 (Pseudotsuga menziesii) 幼苗物候影响时,通过设定不同的土壤湿度國值, 等到土壤湿度低于设定值时再浇水,实现土壤湿度的控制。

在野外,物候控制实验主要改变土壤湿度。例如,利用遮雨棚排除自然降雨干扰,依靠酒水器对喷水量进 行控制, 从而实现土壤湿度的梯度处理 ${ }^{[4]}$ 。另一种方式是利用传感器控制雨水遮蔽系统, 使春夏季雨水流人 量减少 ${ }^{[45]}$ 。在高寒地区, 如西藏中部的高山草甸, 可在植物返青前采用人工补雪的方式增加土壤湿度 ${ }^{[23]}$ 。

\section{5 小结}

综上,物候控制实验的基本方法可总结为图 1。由于不同方法的经济可行性、操作难易程度、耗时、经济 成本等不同, 本研究梳理了不同控制方法的优缺点 (表 1 )。在对所有气候因子的控制实验中,生长箱操作方 便, 应用最为广泛,但受到自身体积的限制多适用于木本植物枝条或幼苗。如果在野外环境下对成年木本植 物开展物候控制实验,需要采用加热电缆、红外辐射器、遮雨棚等成本较高的方案。

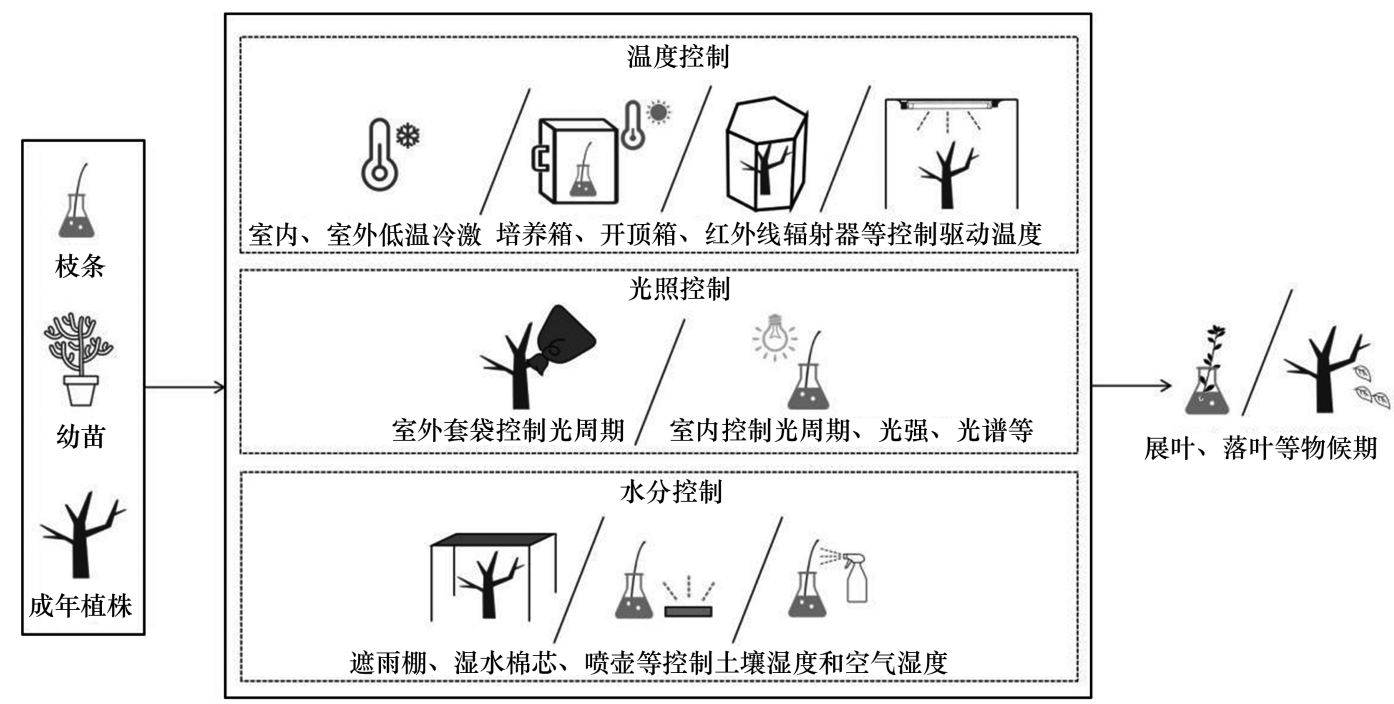

图 1 物候控制实验方法

Fig.1 Methods for controlled experiments in phenological studies

\section{2 春季物候期的影响因子研究进展}

春季物候期主要指多年生植物在春季的芽开放期及之后的开花期与展叶期。多年生植物在经历夏季的 快速生长后, 随着秋季温度的降低和昼长的缩短, 顶端分生组织停止生长, 木本植物长出冬芽、草本植物枯黄, 进人休眠期。通过冬季的低温刺激 ( 又叫冷激), 休眠期解除。休眠期解除后,植物在逐渐回暖的春季开始萌 芽、展叶或开花。对于春季物候期的控制实验,主要针对休眠期的解除阶段与休眠解除后的发育阶段。

2.1 冷激

实验结果表明, 冬季冷激量的增加会加快后续芽开放的速度或降低芽开放的热量需求。例如, Flynn 
等 ${ }^{[31]}$ 在哈佛森林和鬼北克于 2015 年 1 月采集了 28 种木本植物的枝条放人生长箱培养, 给予部分枝条 $1.5^{\circ} \mathrm{C}$ 或 $4^{\circ} \mathrm{C}$ 下 $30 \mathrm{~d}$ 的额外冷激处理,发现额外的冬季冷激使木本植物展叶始期提前了 $15.8 \mathrm{~d}$ 。在爱尔兰,四种木 本植物的枝条在 $3^{\circ} \mathrm{C}$ 下处理不同时长 $(0-105 \mathrm{~d})$ 后, 发现冷激时长的增加促进了萌芽期的提前, 且提高了萌 芽率 ${ }^{[37]}$ 。也有实验利用暴露于自然条件下的冬季低温控制冷激量。例如,在美国乔治亚州,每周采集一次桃 树 (Prunus persica) 的枝条至合适条件下培养,发现后几周采集的枝条由于接受的冷激时间更长,它们的花芽 萌发所需要的热量需求下降,萌芽速率更快、萌芽比例更高 ${ }^{[46]}$ 。Pletsers 等 ${ }^{[47]}$ 将柔毛桦 (Betula pubescens) 和 欧洲山杨 (Populus tremula) 幼苗前后两次 (2009 年 11 月 25 日和 2010 年 1 月 18 日) 移人生长箱培养, 发现冷 激时间长 (第二次采样) 使两个物种的萌芽时间均提前。在加拿大安大略省, 随着冷激累积时长的增加, 7 个 物种萌芽所需的热量也逐渐减少 ${ }^{[48]}$ 。欧洲山毛榉萌芽的热量需求与冷激时长也呈负相关的线性关系 ${ }^{[17]}$ 。 总之,所有控制实验均发现冬季冷激量的增加会使春季物候期提前。

表 1 物候控制实验方法优缺点比较

Table 1 The comparison among the methods of phenological controlled experiments

\begin{tabular}{|c|c|c|c|c|}
\hline $\begin{array}{l}\text { 气候因子 } \\
\text { Climatic factors }\end{array}$ & $\begin{array}{l}\text { 控制方法 } \\
\text { Controlled methods }\end{array}$ & $\begin{array}{l}\text { 优点 } \\
\text { Advantages }\end{array}$ & $\begin{array}{l}\text { 缺点 } \\
\text { Disadvantages }\end{array}$ & $\begin{array}{l}\text { 案例 } \\
\text { Case }\end{array}$ \\
\hline 驱动温度 & 生长箱 & 简便、操作性强 & 体积有限 & [19] \\
\hline \multirow[t]{4}{*}{ Forcing temperature } & 温室 & 简便、经济 & 占用空间大 & [21] \\
\hline & 开顶箱 & 简便、经济 & 面积有限、易受干扰 & {$[23]$} \\
\hline & 加热电缆 & 精确控制温度 & 耗电、加热不均 & [25] \\
\hline & 红外线辐射器 & 精确控制能量输人、不改变小气候 & 耗电、加热面积有限 & [24] \\
\hline 冷激 & 生长箱 & 简便、操作性强 & 体积有限 & [31] \\
\hline Chilling & 间隔时间采样 & 成本低 & 连续采样, 耗时较长 & [32] \\
\hline 光照 & 生长箱 & 简便、操作性强 & 体积有限 & [34] \\
\hline Light & 套袋 & 可用于成年植株 & 袋内温湿度难控制 & {$[36]$} \\
\hline 水分 & 生长箱 & 简便、操作性强 & 体积有限 & [41] \\
\hline Moisture & 遮雨棚 & 适用于野外环境 & 对光照条件产生干扰 & [44] \\
\hline
\end{tabular}

\section{2 驱动温度}

驱动温度指休眠解除后,使植物快速生长发育的较温暖的温度。已有研究表明,驱动温度的升高会促进 植物春季物候期的发生。室内控制实验中, 利用多个生长箱之间的温度差异, 发现温度增加的条件下,木本植 物的萌芽期、展叶期等出现显著提前 ${ }^{[49-50]}$ 。室外开顶箱实验也表明增温使高山草甸地区优势物种的开花期 显著提前 ${ }^{[23]}$ 。增温使北美草原上春季开花的草本植物花期及果期提前, 而在夏季之后开花的物种物候期推 迟 ${ }^{[51]}$, 表明不同季节开花的草本植物对温度具有不同的响应机制。

虽然增温会使植物春季物候期提前, 但是温度对物候期的影响是非线性的,即春季物候的温度敏感度随 温度的升高表现出降低的趋势。例如, Wang 等 ${ }^{[19]}$ 通过对北京 5 种落叶阔叶木本植物的枝条, 在 6 个温度梯 度下进行培养 $\left(5-30^{\circ} \mathrm{C}\right)$, 发现随温度升高, $1^{\circ} \mathrm{C}$ 增温导致的花期提前量下降。类似结论也出现在 $\mathrm{Fu}$ 等 ${ }^{[50]}$ 的 生长箱增温实验中。

以往研究主要针对平均气温,但近年来控制实验关注到增温的具体时段,即白天增温还是夜晚增温对春 季物候期的影响是否存在差异。在同样日均温条件下,昼夜温差对于植物发芽有促进作用,例如,挪威云杉枝 条在昼/夜温度为 $15^{\circ} \mathrm{C} / 5^{\circ} \mathrm{C}$ 的温室中培养比在 $10^{\circ} \mathrm{C}$ 的恒温温室中萌芽更早 ${ }^{[21]}$ 。白天增温与夜晚增温相比, 对物候期的影响更大。例如,不同种源地的黑云杉 ( Picea mariana ) 在生长箱中分别进行白天增温和夜间增温 的处理,发现萌芽期对夜间增温的响应程度小于白天增温 ${ }^{[20]}$ 。在温室条件下观察欧洲白桦、英国栋 ( Quercus robur) 和欧洲山毛榉 3 个树种对白天和夜间增温的响应差异, 结果表明白天和夜间温度的升高都使展叶期显 著提前,但白天增温对展叶期的影响大约是夜间温度的 3 倍 ${ }^{[52]}$ 。类似的结果也出现在 Zhang 等 $^{[53]}$ 的研究中。 


\section{3 光照}

已有证据显示, 较长的光周期能使植物的展叶始期提前, 但这种效应仅限于部分植物。从 2 个北美森林 中 28 种木本植物的研究结果来看,在群落水平上,长光周期 (12 h) 相较于短光周期 (8h) 可使枝条的萌芽期 提前 $5 \mathrm{~d}^{[31]}$ 。Basler 等 ${ }^{[35]}$ 发现不同物种的枝条对光周期的响应不同,对于演替后期物种来说光周期是重要的 环境信号, 而光周期对演替前期物种只发挥微弱的作用。室外实验能够直接在植株上验证光周期的效应。例 如,Zohner 等 ${ }^{[34]}$ 选取种植于慕尼黑植物园的欧洲七叶树、欧洲山毛榉和挪威云杉 3 个物种, 将自然条件下的 光周期延长与固定 $8 \mathrm{~h}$ 不变的光周期相比,发现 $8 \mathrm{~h}$ 的短日照使欧洲山毛榉的萌芽期推迟 $41 \mathrm{~d}$,欧洲七叶树的 萌芽期推迟 $4 \mathrm{~d}$, 而对挪威云杉无影响。最新的研究发现, 在冷激程度低的情况下, 北半球 173 个物种中只有 $35 \%$ 萌芽期会受到春季光周期的调节作用,且这些植物主要起源于冬季相对较短的低纬度地区 ${ }^{[54]}$ 。

光照强度的增加会促进植物的萌芽。在温室中使用遮阳布与正常条件相比, 光照强度的增加促进了挪威 云杉的萌芽, 可能是由于晴天吸收辐射能量引起植物表面温度升高的结果 ${ }^{[38]}$ 。同样利用遮光罩降低光照强 度的实验中, 随着光照强度的降低, 欧洲山毛榉萌芽期显著推迟 ${ }^{[37]}$ 。

光谱成分 (例如 R:FR 比、蓝光与紫外线的比例) 等对物候也具有显著的影响。在生长箱中通过白炽灯和 苂光灯形成红光: 远红外 (R:FR) 为 0.58 的光照,与自然光进行对比,结果表明低比例的 R:FR 使桦木萌芽期 提前了 $4 \mathrm{~d}^{[40]}$ 。将包含和排除蓝光的光照条件进行对比, 发现蓝光促进了落叶阔叶树种的萌芽 ${ }^{[39]}$ 。此外, 在 野外实验中增加 $30 \%$ 的紫外线也促进了欧洲山杨雄株萌芽期的显著提前 ${ }^{[55]}$ 。

\section{4 水分}

空气湿度对植物春季物候的影响存在一定的争议。有实验发现, 空气湿度的增加会促进植物春季物候期 的发生。例如, Laube 等 ${ }^{[42]}$ 选取了 9 种北半球的木本植物, 将它们的枝条放人生长箱进行培养, 设置 $40 \%$ 、 90\%两种空气湿度, 同时保持温度、光周期等其他因子保持一致, 发现空气湿度的降低会推迟展叶期。但是, 之后的研究发现, 在美国马萨诸塞州,包括 5 种人侵灌木、 6 种本地灌木、 3 个本地树种、 1 种非本地的观赏种 在内的 15 种树并没有表现出展叶期随空气湿度增加而提前的趋势 ${ }^{[41]}$ 。后一研究与 Laube ${ }^{\text {等 }}{ }^{[42]}$ 的差异可能 是由于 Laube 等实验中的温度存在昼夜变化, 导致空气湿度随之出现短暂的变化。Zohner 等 ${ }^{[56]}$ 同样利用控 制实验研究了空气湿度对 10 种木本植物展叶期的影响, 发现空气湿度不是温带木本植物春季展叶的触发条 件。植物物候期对空气湿度的响应还需要通过更多物种及实验验证。

土壤湿度是影响植物春季物候期的潜在因子, 特别对处于干旱半干旱地区的草原。Zhou 等 $^{[44]}$ 在沿降水 梯度分布的荒漠草原、典型草原和草甸草原上利用洒水器设置湿度梯度, 每 $5 \mathrm{~d}$ 观测一次非禾本科萌芽及开 花、禾本科抽穗或雄莣显露情况,结果表明,土壤湿度的降低会推迟开花期,而增加降水会使开花期提前。在 木本植物方面, 实验发现土壤湿度对英国栋、柔毛栋和冬青柇 ( Quercus ilex) 幼苗的展叶始期没有显著 影响 ${ }^{[45]}$ 。

\section{5 多因子交互效应}

除单因子的影响外,实验结果还发现不同气候因子对春季物候期的影响存在交互效应。一个明显的结论 是, 冷激不足的时候, 光周期的效应更明显。Partanen 等 ${ }^{[21]}$ 发现当冷激时长不足时, 光周期的延长会降低挪 威云杉的积温需求; 但在经过较长的冷激时段后 $\left(105 \mathrm{~d}\right.$ ), 光周期对萌芽期的影响变得不明显。Laube 等 ${ }^{[32]}$ 也 发现只有冷激不足时, 所有物种的萌芽期才对光周期的增加有显著响应, 且随着冷激程度的增加, 对光周期响 应的物种数急剧减少。

冷激不足的时候, 增温对春季物候期提前的效应更明显。当冬季冷激程度低时,植物春季物候的积温需 求随之增加, 更高的积温需求会使同等增温时物候期的变化变大。Wang 等 ${ }^{[57]}$ 以连翅 (Forsythia suspense) 为 例, 发现由于冬季冷激量的不足使开花的积温需求增加, 使同样 $3^{\circ} \mathrm{C}$ 增温引起的开花始期提前量更大。

\section{3 秋季物候期的影响因子研究进展}

在北半球温带地区, 秋季昼长逐渐缩短和温度逐步降低, 植物的生长中止直至进入休眠期。秋季物候的 
控制实验主要针对木本植物的冬芽形成、草本与木本植物叶变色、落叶等相对容易观测的物候期。

\section{1 温度}

实验表明,低温会促进植物进人休眠期。Heide 等 ${ }^{[58]}$ 通过控制实验发现苹果 (Malus pumila) 和梨 (Pyrus communis $)$ 幼苗在低温 $\left(<12^{\circ} \mathrm{C}\right)$ 环境下出现了明显的生长中止、冬芽形成、叶片变黄和脱落现象。秋季植物叶 片衰老和黄枯的推迟是对增温实验最普遍的响应 ${ }^{[59]}$, 在 $2^{\circ} \mathrm{C}$ 和 $4^{\circ} \mathrm{C}$ 的增温条件下, 加拿大黄桦 (Betula alleghaniensis)、大齿杨(Populus grandidentata)、北美红栋( Quercus rubra)、北美枫香 (Liquidambar styraciflua) 等四个温带物种的平均落叶期分别推迟了 $8 \mathrm{~d}$ 和 $13 \mathrm{~d}^{[60]} 。 4^{\circ} \mathrm{C}$ 的增温条件下美国红枫 (Acer rubrum) 和糖枫 (A. saccharum) 落叶期分别推迟 $7.5 \mathrm{~d}$ 和 $13 \mathrm{~d}^{[61]}$ 。但在北极地区, 增温对柳属 (Salix spp.) 3 个物种的叶变色 期没有影响 ${ }^{[62]}$ 。

值得注意的是, 昼夜增温可能对秋季物候期的影响存在相反的效应。Kalcsits 等 ${ }^{[63]}$ 在加拿大中部选择小 黑杨 (Populus spp.) 为对象, 在生长箱中设置了四种不同的昼/夜温度, 发现在短昼长的条件下, 夜间温度的升 高会使休眠期提前,但是白天温度的升高则使休眠期推迟。

此外,实现发现温度对秋季物候期的影响可能存在滞后与联动效应。例如, $\mathrm{Fu}$ 等 ${ }^{[64]}$ 发现前一年冬春季 的增温使英国栋和欧洲山毛榉的幼苗展叶期提前后,在当年的叶变色期也会比未受增温影响的幼苗提前。

3.2 光照

短日照是促使多年生植物进人休眠的重要环境信号。短日照是诱导桑树 (Morus alba) 进人自然休眠的 主要因子, 在长日照条件下即使进行低温处理桑树仍不能进入休眠 ${ }^{[65]}$ 。单一的短日照条件也可诱导杨树 (Populus deltoides) 进人休眠 ${ }^{[66]}$ 。但实验表明, 日照长度对苹果、梨和榆树 (Ulmus spp.) 的休眠没有影响, 低温 才是它们进人休眠的关键因子 ${ }^{[67]}$ 。因此, 只有部分植物的秋季物候期对短日照敏感。

除光周期外,研究发现光照强度的降低会推迟秋季物候期。在美国哈佛森林的一项研究发现,使用遮光 布降低光照强度可以有效减缓木本植物秋季叶绿素和花青素的下降, 推迟秋季叶片的衰老 ${ }^{[68]}$ 。类似的结果 也在北美红栋的遮荫实验中得到 ${ }^{[69]}$ 。

除了光照强度外,光谱成分也对秋季物候有影响。例如, Molmann 等 ${ }^{[70]}$ 发现在蓝光照射下, 种源地分别 为 $69^{\circ} \mathrm{N} 、 64^{\circ} \mathrm{N}$ 和 $59^{\circ} \mathrm{N}$ 的挪威云杉形成冬芽的时间分别推迟了 $4 \mathrm{~d} 、 7 \mathrm{~d}$ 和 $3 \mathrm{~d}$ 。

\section{3 水分}

目前,关于水分条件对秋季物候期的控制实验较少。已有证据表明,较低的土壤湿度会促使温带草地在 夏季遭受干旱时的叶片表面温度升高, 导致叶片衰老更快 ${ }^{[71]}$ 。在瑞士的室外开顶箱实验中, 利用雨棚隔绝自 然降雨并通过人工降雨器控制开顶箱内降水, 发现栋树 ( Quercus spp.) 幼苗在水分减少的环境下, 落叶更 早 ${ }^{[72]}$ 。因此,植物在遭受水分胁迫时,可能会通过落叶的形式降低自身水分消耗。

\section{4 讨论}

4.1 控制实验结果与地面观测的对比

控制实验能够排除其他因素干扰, 强调单一因素的影响。实际上, 在地面物候观测数据中,物候变化通常 是多因子综合作用的结果。地面物候变化的归因分析主要是基于物候期与其他因子之间的相关与回归分析。 为验证实验结果的可信性, 本文把控制实验得到的结论与地面物候观测数据得到的结果简要进行了对比。

长时间的物候定位观测序列显示, 春季气温与展叶期、开花期等显著负相关, 如利用中国物候观测网的观 测数据发现, 1987-2016 年西安和宝鸡 21 种木本植物的开花期均与花期前 1 到 2 个月的气温显著负相 关 ${ }^{[1]}$ 。欧洲与美国物候观测网的数据也得到了类似的结果 ${ }^{[73]}$ 。这与控制实验中驱动温度的效应相一致。 欧洲地区 1980-2014 年的木本植物展叶始期数据显示, 展叶始期受春季温度增高的影响显著提前, 但秋冬季 温度的升高会降低冷激量推迟展叶始期 ${ }^{[74]}$, 这也与实验得到的冷激效应相一致。

基于中国物候观测网 17 个站点的地面观测资料,研究表明近 40 年,中国东部地区木本植物秋季叶全变 
色期变化总体表现为推迟的趋势, 最低气温每升高 $1^{\circ} \mathrm{C}$, 植物叶全变色期平均推迟约 $3 \mathrm{~d}^{[75]}$ 。同时, Piao 等 ${ }^{[76]}$ 通过遥感数据发现, 1982-1999 年中国温带地区植物秋季平均温度每升高 $1^{\circ} \mathrm{C}$, 植物休眠期推迟 $3.8 \mathrm{~d} 。$ 地面 物候观测和遥感数据发现的增暖使秋季物候期推迟的效应与控制实验中低温诱导植物提前进人休眠相一致。

\section{2 农作物物候控制实验}

本研究主要针对自然植物物候的控制实验开展综述。除此之外, 农作物物候与产量密切相关, 也具有重 要研究价值。已有研究对小麦、水稻、大豆等作物的物候期开展了控制实验。例如,有研究采用开放式主动增 温系统对水稻进行夜间增温试验,揭示了夜间温度升高对水稻生育期的影响 ${ }^{[77]}$ 。Zhang 等 $^{[78]}$ 利用红外加热 器控制大田温度,探讨了大豆物候对气候变化的响应。作物物候的控制实验中还会通过设置不同的播种期来 研究播种期对后续生育期变化的影响 ${ }^{[79]}$ 。因农作物物候受人为管理措施(如播种期的选择、品种的更替) 影 响较大, 控制实验的侧重点主要集中在如何优化人为管理措施以提高产量。自然植物的物候控制实验主要目 的是为探讨气候因子对物候的作用机制, 与农作物物候研究存在明显区别, 因此本文并未对农作物物候控制 实验开展详尽的综述。

\section{5 结论与展望}

现有物候控制实验对春季物候的响应机制研究较为充分。增温对多年生植物春季物候期的影响有双重 效应。冬季增温导致的冷激量减少会使春季物候期发生所需的积温增加,有推迟效应; 而春季驱动温度的升 高则使积温累积更快, 对春季物候期有提前效应。从现有长时间物候观测序列看,春季物候期呈提前趋势的 占据了多数 ${ }^{[80]}$, 意味着春季增温的提前效应大于冬季增温的推迟效应。春季白天增温的效应大于夜间增温。 空气湿度对春季物候期的影响存在争议,但土壤湿度、昼长以及光照强度的增加会促进部分植物春季物候期 的提前。值得注意的是, 各因子对春季物候的影响存在交互作用, 当冷激不足时, 光周期和增温的效应更 明显。

控制实验对秋季物候的研究较为薄弱,但仍然获得了一些基本结论。低温和光周期的缩短是导致多年生 植物秋季物候 (叶片衰老) 的关键因子, 水分胁迫下植物也会提前变色与落叶。因此,增温与干旱对秋季物候 期有相反的效应。秋季物候期的变化趋势取决于各因子在特定地理区域的影响力,这也是过去几十年来秋季 物候期的变化趋势一致性较弱的原因。

未来的物候控制实验研究可从以下几个方面深人开展:

(1) 在针对木本植物春季物候期的控制实验中, 需要快速的诊断休眠期是否已经建立 (即判断木本植物 在秋季进人休眠的时间点), 这关系到计算冷激量时的起始时间。在休眠建立后,如何量化休眠期的冷激量。 目前已经提出了多种需冷量的算法 ${ }^{[81]}$, 这些算法的有效性与适用性需要利用控制实验进一步评估。另外, 还 需考虑如何利用控制实验判断多年生植物是否存在明显的休眠解除时间点以及昼长的增加是否对春季物候 期的积温累积有补偿效应等问题。这些问题的解决对于实现春季物候期的精准建模与未来气候变化下预测 具有重要意义。

(2) 在针对木本植物秋季物候的控制实验中, 低温与短日照是单独作用还是存在一定的交互作用还有待 研究。几个急需解决的问题是: 对光周期敏感的物种, 使植物叶片衰老的光周期阈值是否存在? 如果植物在 低于一定昼长阈值时开始进人休眠, 阈值存在怎样的地理差异? 水分条件的变化及其与温度的耦合会在多大 程度影响秋季物候期? 深人探究温度、光周期和水分对植物叶片衰老的作用, 有助于理解生态系统生长季的 结束时间对气候变化的响应。

(3) 对草本植物春秋季物候的影响因子仍需深人研究。草本植物多分布于干旱半干旱地区的草原。与 木本植物相比, 草本植物生长更容易受到水分条件的影响, 而土壤湿度如何影响草本植物的萌芽期与枯黄期 仍不清楚。揭示草本植物物候对气候因子的响应机制对于草地生态系统管理具有重要意义。 


\section{参考文献 (References) :}

［1］ 中国气象局气候变化中心. 中国气候变化蓝皮书(2020). 北京: 科学出版社, 2020 .

[ 2 ] Parmesan C, Yohe G. A globally coherent fingerprint of climate change impacts across natural systems. Nature, 2003, 421 (6918) : 37-42.

[ 3 ] Root T L, Price J T, Hall K R, Schneider S H, Rosenzweig C, Pounds J A. Fingerprints of global warming on wild animals and plants. Nature, 2003, 421(6918): 57-60.

[ 4 ] Wang H J, Dai J H, Ge Q S. The spatiotemporal characteristics of spring phenophase changes of Fraxinus chinensis in China from 1952 to 2007. Science China Earth Sciences, 2012, 55(6): 991-1000.

[ 5 ] 陆佩玲, 于强, 贺庆棠. 植物物候对气候变化的响应. 生态学报, 2006, 26(3): 923-929.

[6] 方精云, 朱江玲, 石岳. 生态系统对全球变暖的响应. 科学通报, 2018, 63(2): 136-140.

[ 7 ] Richardson A D, Keenan T F, Migliavacca M, Ryu Y, Sonnentag O, Toomey M. Climate change, phenology, and phenological control of vegetation feedbacks to the climate system. Agricultural and Forest Meteorology, 2013, 169: 156-173.

[ 8 ] Cleland E E, Chuine I, Menzel A, Mooney H A, Schwartz M D. Shifting plant phenology in response to global change. Trends in Ecology \& Evolution, 2007, 22(7): 357-365

[ 9 ] 王焕昫, 陶泽兴, 葛全胜. 气候波动对西安 39 种木本植物展叶始期及其积温需求的影响. 植物生态学报, 2019, 43(10): 877-888.

［10］陶泽兴, 葛全胜, 王焕畑. 1963-2018 年中国垂柳和榆树开花始期积温需求的时空变化. 地理学报, 2020, 75(7)：1451-1464.

[11］陶泽兴, 葛全胜, 徐韵佳, 王焕昫. 西安和宝鸡木本植物花期物候变化及温度敏感度对比. 生态学报, 2020, 40(11): 3666-3676.

[12] Fu Y H, Zhang X, Piao S L, Hao F H, Geng X J, Vitasse Y, Zohner C, Peñuelas J, Janssens I A. Daylength helps temperate deciduous trees to leaf-out at the optimal time. Global Change Biology, 2019, 25(7): 2410-2418.

[13] 杨晓芳, 陈效述, 罗翔中. 锡林郭勒草原遥感植被物候的地面照相验证. 草业科学, 2015, 32(5): 667-674.

[14] Petach A R, Toomey M, Aubrecht D M, Richardson A D. Monitoring vegetation phenology using an infrared-enabled security camera. Agricultural and Forest Meteorology, 2014, 195-196: 143-151.

[15] Tao Z X, Xu Y J, Dai J H, Wang H J. Divergent response of leaf coloring seasons to temperature change in northern China over the past 50 years. Advances in Meteorology, 2019, 2019: 2706803.

[16] 董晓宇, 姚华荣, 戴君虎, 朱梦瑶. 2000-2017 年内蒙古荒漠草原植被物候变化及对净初级生产力的影响. 地理科学进展, 2020,39 (1) : 24-35.

[17] Vitasse Y, Basler D. What role for photoperiod in the bud burst phenology of European beech. European Journal of Forest Research, 2012 , 132 (1) : $1-8$.

[18] Delpierre N, Lireux S, Hartig F, Camarero J J, Cheaib A, Čufar K, Cuny H, Deslauriers A, Fonti P, Gričar J, Huang J G, Krause C, Liu G H, de Luis M, Mäkinen H, del Castillo E M, Morin H, Nöjd P, Oberhuber W, Prislan P, Rossi S, Saderi S M, Treml V, Vavrick H, Rathgeber C B K. Chilling and forcing temperatures interact to predict the onset of wood formation in Northern Hemisphere conifers. Global Change Biology, 2019, 25(3) : 1089- 1105 .

[19] Wang H, Tao Z X, Wang H J, Ge Q S. Varying temperature sensitivity of bud-burst date at different temperature conditions. International Journal of Biometeorology, 2021, 65(3): 357-367.

[20] Rossi S, Isabel N. Bud break responds more strongly to daytime than night-time temperature under asymmetric experimental warming. Global Change Biology, 2017, 23(1): 446-454.

[21] Partanen J, Koski V, Hänninen H. Effects of photoperiod and temperature on the timing of bud burst in Norway spruce (Picea abies). Tree Physiology, 1998, 18(12): 811-816.

[22] 侯彦会, 周广胜, 许振柱. 基于红外增温的草地生态系统响应全球变暖的研究进展. 植物生态学报, 2013, 37(12): 1153-1167.

[23] Dorji T, Hopping K A, Meng F D, Wang S P, Jiang L L, Klein J A. Impacts of climate change on flowering phenology and production in alpine plants: the importance of end of flowering. Agriculture, Ecosystems \& Environment, 2020, 291: 106795.

[24] 珊丹. 控制性增温和施氮对荒漠草原植物群落和土壤的影响 [D]. 呼和浩特: 内蒙古农业大学, 2008.

[25] Nakamura M, Muller O, Tayanagi S, Nakaji T, Hiura T. Experimental branch warming alters tall tree leaf phenology and acorn production. Agricultural and Forest Meteorology, 2010, 150(7/8): 1026-1029.

[26] Dao M C E, Rossi S, Walsh D, Morin H, Houle D. A 6-year-long manipulation with soil warming and canopy nitrogen additions does not affect xylem phenology and cell production of mature black spruce. Frontiers in Plant Science, 2015, 6: 877.

[27] Horvath D P, Anderson J V , Chao W S, Foley M E. Knowing when to grow: signals regulating bud dormancy. Trends in Plant Science, 2003, 8 (11) : 534-540.

[28] Sparks D. Chilling and heating model for pecan budbreak. Journal of the American Society for Horticultural Science, 1993, 118(1): 29-35.

[29] Myking T, Heide O M. Dormancy release and chilling requirement of buds of latitudinal ecotypes of Betula pendula and B. pubescens. Tree Physiology, 1995, 15(11): 697-704.

[30] Ruiz D, Campoy J A, Egea J. Chilling and heat requirements of apricot cultivars for flowering. Environmental and Experimental Botany, 2007, 61 (3) : 254-263.

[31] Flynn D F B, Wolkovich E M. Temperature and photoperiod drive spring phenology across all species in a temperate forest community. New 
Phytologist, 2018, 219(4) : 1353-1362.

[32] Laube J, Sparks T H, Estrella N, Höfler J, Ankerst D P, Menzel A. Chilling outweighs photoperiod in preventing precocious spring development. Global Change Biology, 2014, 20(1): 170-182.

[33] Du Y J, Pan Y Q, Ma K P. Moderate chilling requirement controls budburst for subtropical species in China. Agricultural and Forest Meteorology, 2019, 278: 107693.

[34] Zohner C M, Renner S S. Perception of photoperiod in individual buds of mature trees regulates leaf-out. New Phytologist, 2015, 208 (4) : 1023-1030.

[35] Basler D, Körner C. Photoperiod sensitivity of bud burst in 14 temperate forest tree species. Agricultural and Forest Meteorology, 2012, 165: 73-81.

[36] Fu Y H, Piao S L, Zhou X C, Geng X J, Hao F H, Vitasse Y, Janssens I A. Short photoperiod reduces the temperature sensitivity of leaf-out in saplings of Fagus sylvatica but not in horse chestnut. Global Change Biology, 2019, 25(5): 1696-1703.

[37] Caffarra A, Donnelly A. The ecological significance of phenology in four different tree species: effects of light and temperature on bud burst. International Journal of Biometeorology, 2011, 55(5): 711-721.

[38] Partanen J, Leinonen I, Repo T. Effect of accumulated duration of the light period on bud burst in Norway spruce (Picea abies) of varying ages. Silva Fennica, 2001, 35(1): 111-117.

[39] Brelsford C C, Robson T M. Blue light advances bud burst in branches of three deciduous tree species under short-day conditions. Trees, 2018, 32 (4) : 1157-1164.

[40] Linkosalo T, Lechowicz M J. Twilight far-red treatment advances leaf bud burst of silver birch (Betula pendula). Tree Physiology, 2006, 26( 10) : 1249-1256.

[41] Zipf L, Primack R B. Humidity does not appear to trigger leaf out in woody plants. International Journal of Biometeorology, 2017, 61 (12): 2213-2216.

[42] Laube J, Sparks T H, Estrella N, Menzel A. Does humidity trigger tree phenology? Proposal for an air humidity based framework for bud development in spring. New Phytologist, 2014, 202(2) : 350-355.

[43] Khan S R, Rose R, Haase D L, Sabin T E. Soil water stress: its effects on phenology, physiology, and morphology of containerized Douglas-fir seedlings. New Forests, 1996, 12(1): 19-39.

[44] Zhou Z X, Li Y, Song J, Ru J Y, Lei L J, Zhong M X, Zheng M M, Zhang A, Hui D F, Wan S Q. Growth controls over flowering phenology response to climate change in three temperate steppes along a precipitation gradient. Agricultural and Forest Meteorology, 2019, 274: 51-60.

[45] Morin X, Roy J, Sonié L, Chuine I. Changes in leaf phenology of three European oak species in response to experimental climate change. New Phytologist, 2010, 186(4) : 900-910.

[46] Okie W R, Blackburn B. Increasing chilling reduces heat requirement for floral budbreak in peach. HortScience, 2011, 46(2) : $245-252$.

[47] Pletsers A, Caffarra A, Kelleher C T, Donnelly A. Chilling temperature and photoperiod influence the timing of bud burst in juvenile Betula pubescens Ehrh. and Populus tremula L. trees. Annals of Forest Science, 2015, 72(7) : 941-953.

[ 48] Man R Z, Lu P X, Dang Q L. Insufficient chilling effects vary among boreal tree species and chilling duration. Frontiers in Plant Science, 2017, 8: 1354.

[49] Caffarra A, Donnelly A, Chuine I, Jones M B. Modelling the timing of Betula pubescens budburst. I. Temperature and photoperiod: a conceptual model. Climate Research, 2011, 46(2): 147-157.

[50] Fu Y H, Campioli M, Deckmyn G, Janssens I A. Sensitivity of leaf unfolding to experimental warming in three temperate tree species. Agricultural and Forest Meteorology, 2013, 181: 125-132.

[51] Sherry R A, Zhou X H, Gu S L, Arnone III J A, Schimel D S, Verburg P S, Wallace L L, Luo Y Q. Divergence of reproductive phenology under climate warming. Proceedings of the National Academy of Sciences of the United States of America, 2007, 104(1): 198- 202.

[52] Fu Y H, Liu Y J, De Boeck H J, Menzel A, Nijs I, Peaucelle M, Peñuelas J, Piao S L, Janssens I A. Three times greater weight of daytime than of night-time temperature on leaf unfolding phenology in temperate trees. New Phytologist, 2016, 212(3) : 590-597.

[53] Zhang S K, Isabel N, Huang J G, Ren H, Rossi S. Responses of bud-break phenology to daily-asymmetric warming: daytime warming intensifies the advancement of bud break. International Journal of Biometeorology, 2019, 63(12): 1631-1640.

[54] Zohner C M, Benito B M, Svenning J C, Renner S S. Day length unlikely to constrain climate-driven shifts in leaf-out times of northern woody plants. Nature Climate Change, 2016, 6(12): 1120-1123.

[55 ] Strømme C, Sivadasan U, Nissinen K, Lavola A, Randriamanana T, Julkunen-Tiitto R, Nybakken L. Interannual variation in UV-B and temperature effects on bud phenology and growth in Populus tremula. Plant Physiology and Biochemistry, 2019, 134: 31-39.

[56] Zohner C M, Strauß A F T, Baumgarten F, Vitasse Y, Renner S S. Rising air humidity during spring does not trigger leaf-out in temperate woody plants. New Phytologist, 2020, 225(1): 16-20.

[57] Wang H J, Wang H, Ge Q S, Dai J H. The interactive effects of chilling, photoperiod, and forcing temperature on flowering phenology of temperate woody plants. Frontiers in Plant Science, 2020, 11: 443.

[58] Heide O M, Prestrud A K. Low temperature, but not photoperiod, controls growth cessation and dormancy induction and release in apple and pear. Tree Physiology, 2005, 25(1): 109-114. 
[59] Chung H, Muraoka H, Nakamura M, Han S, Muller O, Son Y. Experimental warming studies on tree species and forest ecosystems: a literature review. Journal of Plant Research, 2013, 126(4): 447-460.

[60] Gunderson C A, Edwards N T, Walker A V, O'Hara K H, Campion C M, Hanson P J. Forest phenology and a warmer climate-growing season extension in relation to climatic provenance. Global Change Biology, 2012, 18(6) : 2008-2025.

[61] Norby R J, Hartz-Rubin J S, Verbrugge M J. Phenological responses in maple to experimental atmospheric warming and $\mathrm{CO}_{2}$ enrichment. Global Change Biology, 2003, 9(12): 1792-1801.

[62] Jones M H, Bay C, Nordenhäll U. Effects of experimental warming on arctic willows ( Salix spp.) : a comparison of responses from the Canadian High Arctic, Alaskan Arctic, and Swedish Subarctic. Global Change Biology, 1997, 3( S1) : 55-60.

[63] Kalcsits L A, Silim S, Tanino K. Warm temperature accelerates short photoperiod-induced growth cessation and dormancy induction in hybrid poplar (Populus $\times$ spp.). Trees, 2009, 23(5): 971-979.

[64] Fu Y S, Campioli M, Vitasse Y, De Boeck H J, Van den Berge J, AbdElgawad H, Asard H, Piao S L, Deckmyn G, Janssens I A. Variation in leaf flushing date influences autumnal senescence and next year's flushing date in two temperate tree species. Proceedings of the National Academy of Sciences of the United States of America, 2014, 111(20): 7355-7360.

[65] 简令成, 卢存福, 邓江明, 李积宏, Li P H. 木本植物休眠的诱导因子及其细胞内 $\mathrm{Ca}^{2+}$ 水平的调节作用. 应用与环境生物学报, 2004 , 10 (1) : 1-6.

[66] Jian L C, Li P H, Sun L H, Chen T H H. Alterations in ultrastructure and subcellular localization of Ca ${ }^{2+}$ in poplar apical bud cells during the induction of dormancy. Journal of Experimental Botany, 1997, 48(6) : 1195- 1207.

[67] Ghelardini L, Santini A, Black-Samuelsson S, Myking T, Falusi M. Bud dormancy release in elm (Ulmus spp.) clones-a case study of photoperiod and temperature responses. Tree Physiology, 2010, 30(2) : 264-274.

[68] Lee D W, O'Keefe J, Holbrook N M, Feild T S. Pigment dynamics and autumn leaf senescence in a New England deciduous forest, eastern USA. Ecological Research, 2003, 18(6): 677-694.

[69] Cavender-Bares J, Potts M, Zacharias E, Bazzaz F A. Consequences of $\mathrm{CO}_{2}$ and light interactions for leaf phenology, growth, and senescence in Quercus rubra. Global Change Biology, 2000, 6(8): 877-887.

[70] Mølmann J A, Junttila O, Johnsen Ø, Olsen J E. Effects of red, far-red and blue light in maintaining growth in latitudinal populations of Norway spruce (Picea abies). Plant, Cell \& Environment, 2006, 29(2) : 166-172.

[71] Berwaers S, De Boeck H J, Nijs I. End-of-season senescence in grassland species can be traced to leaf temperature during preceding summer drought. Perspectives in Plant Ecology, Evolution and Systematics, 2019, 38: 31-38.

[72] Günthardt-Goerg M S, Kuster T M, Arend M, Vollenweider P. Foliage response of young central European oaks to air warming, drought and soil type. Plant Biology, 2013, 15(S1): 185-197.

[73] Menzel A, Sparks T H, Estrella N, Koch E, Aasa A, Ahas R, Alm-Kübler K, Bissolli P, Braslavská O, Briede A, Chmielewski F M, Crepinsek Z, Curnel Y, Dahl Å, Defila C, Donnelly A, Filella Y, Jatczak K, Måge F, Mestre A, Nordli Ø, Peñuelas J, Pirinen P, Remišová V, Scheifinger H, Striz M, Susnik A, Van Vliet A J H, Wielgolaski F E, Zach S, Zust A. European phenological response to climate change matches the warming pattern. Global Change Biology, 2006, 12(10): 1969-1976.

[74] 林少植, 葛全胜, 王焕炣. 欧洲典型树种展叶始期的时空变化及其对气候变化的响应. 应用生态学报, 2021, 32(3): 788-798.

[75] 郑景云, 葛全胜, 赵会霞. 近 40 年中国植物物候对气候变化的响应研究. 中国农业气象, 2003, 24(1):28-32.

[76] Piao S L, Fang J Y, Zhou L M, Ciais P, Zhu B. Variations in satellite-derived phenology in China's temperate vegetation. Global Change Biology, $2006,12(4): 672-685$.

[77] 张金金, 陈金, 江瑜, 邓艾兴, 宋振伟, 郑成岩, 张卫建. 夜间增温对江苏不同年代水稻主栽品种生育期和产量的影响. 应用生态学报, $2014,25(5): 1349-1356$.

[78] Zhang L X, Zhu L L, Yu M Y, Zhong M X. Warming decreases photosynthates and yield of soybean [Glycine max ( L.) Merrill] in the North China Plain. The Crop Journal, 2016, 4(2): 139-146.

[79] 杨洪宾, 徐成忠, 李春光, 李福元. 播期对冬小麦生长及所需积温的影响. 中国农业气象, 2009, 30(2) : 201-203.

[80] Ge Q S, Wang H J, Rutishauser T, Dai J H. Phenological response to climate change in China: a meta-analysis. Global Change Biology, 2015, 21 (1) : 265-274.

[81] Wang H J, Wu C Y, Ciais P, Peñuelas J, Dai J H, Fu Y S, Ge Q S. Overestimation of the effect of climatic warming on spring phenology due to misrepresentation of chilling. Nature Communications, 2020, 11(1): 4945. 